\title{
Determinant Factors of Physical Fitness in European Children
}

Zaqout, Mahmoud; Vyncke, Krishna; Moreno, Luis A.; Miguel-Etayo, Pilar; Lauria, Fabio; Molnar, Dénes; Lissner, Lauren; Hunsberger, Monica; Veidebaum, Toomas; Tornaritis, Michael; Reisch, Lucia A.; Bammann, Karin; Sprengeler, Ole; Ahrens, Wolfgang; Michels, Nathalie

Document Version

Accepted author manuscript

Published in:

International Journal of Public Health

DOI:

10.1007/s00038-016-0811-2

Publication date:

2016

License

Unspecified

Citation for published version (APA):

Zaqout, M., Vyncke, K., Moreno, L. A., Miguel-Etayo, P., Lauria, F., Molnar, D., Lissner, L., Hunsberger, M., Veidebaum, T., Tornaritis, M., Reisch, L. A., Bammann, K., Sprengeler, O., Ahrens, W., \& Michels, N. (2016). Determinant Factors of Physical Fitness in European Children. International Journal of Public Health, 61(5), 573-582. https://doi.org/10.1007/s00038-016-0811-2

Link to publication in CBS Research Portal

\section{General rights}

Copyright and moral rights for the publications made accessible in the public portal are retained by the authors and/or other copyright owners and it is a condition of accessing publications that users recognise and abide by the legal requirements associated with these rights.

Take down policy

If you believe that this document breaches copyright please contact us (research.lib@cbs.dk) providing details, and we will remove access to the work immediately and investigate your claim. 


\section{Determinant Factors of Physical Fitness in European Children}

Mahmoud Zaqout, Krishna Vyncke, Luis A. Moreno, Pilar Miguel-Etayo, Fabio Lauria, Dénes Molnar, Lauren Lissner, Monica Hunsberger, Toomas Veidebaum, Michael Tornaritis, Lucia A. Reisch, Karin Bammann, Ole Sprengeler, Wolfgang Ahrens, and Nathalie Michels

Journal article (Postprint version)

Cite: Determinant Factors of Physical Fitness in European Children. / Zaqout, Mahmoud; Vyncke, Krishna; Moreno, Luis A.; Miguel-Etayo, Pilar; Lauria, Fabio; Molnar, Dénes; Lissner, Lauren; Hunsberger, Monica; Veidebaum, Toomas; Tornaritis, Michael; Reisch, Lucia A.; Bammann, Karin; Sprengeler, Ole; Ahrens, Wolfgang; Michels, Nathalie. In: International Journal of Public Health, 04 April 2016. http://dx.doi.org/10.1007/s00038-016-0811-2

Uploaded to Research@CBS: June २०16 


\section{Determinant factors of physical fitness in European children. The IDEFICS study}

Mahmoud Zaqout ${ }^{1}$, Krishna Vyncke ${ }^{1}$, Luis A. Moreno², Pilar De Miguel-Etayo ${ }^{2}$, Fabio Lauria ${ }^{3}$, Denes Molnar ${ }^{4}$, Lauren Lissner ${ }^{5}$, Monica Hunsberger ${ }^{5}$, ToomasVeidebaum ${ }^{6}$, Michael Tornaritis ${ }^{7}$, Lucia A. Reisch ${ }^{8}$, Karin Bammann ${ }^{9,10}$, Ole Sprengeler ${ }^{10}$, Wolfgang Ahrens ${ }^{10}$, Nathalie Michels ${ }^{1}$. On behalf of the IDEFICS consortium.

1. Department of Public Health, Faculty of Medicine and Health Sciences, Ghent University, Ghent, Belgium.

2. GENUD (Growth, Exercise, Nutrition and Development) Research Group, EU Ciencias de la Salud, Universidad de Zaragoza, Zaragoza, Spain.

3. Epidemiology \& Population Genetics, Institute of Food Sciences-CNR, Avellino, Italy.

4. Department of Pediatrics, University of Pécs, Pécs, Hungary.

5. Section for Epidemiology and Social Medicine (EPSO), Sahlgrenska Academy, University of Gothenburg, Gothenburg, Sweden

6. Department of Chronic Diseases, National Institute for Health Development, Tallinn, Estonia.

7. Research and Education Institute of Child Health, Strovolos, Cyprus.

8. Copenhagen Business School, Department of Intercultural Communication and Management, Frederiksberg, Denmark.

9. Institute for Public Health and Nursing Research, Faculty for Human and Health Sciences, University of Bremen, Bremen, Germany.

10. Leibniz-Institute for Prevention Research and Epidemiology BIPS, Bremen, Germany.

Correspondence: Mahmoud Zaqout, Department of Public Health, Faculty of Medicine and Health Sciences, Ghent University, Ghent, Belgium. Tel 00329332 8376, Fax 003293324994. email: mahmoud.zaqout@ugent.be 


\section{Abstract \\ Objective:}

This study was designed to explore the determinants of physical fitness in European children aged 6 - 11 years cross-sectionally and longitudinally.

\section{Methods:}

4903 children (50.6\% girls) had sufficient data on measured physical fitness (cardio-respiratory, muscular strength, flexibility, balance, and speed) and possible determinants related to child characteristics, child lifestyle and parental factors. Multivariate and mixed linear regression models were conducted.

\section{Results:}

Age, sex, children's BMI and physical activity were independent and strong determinants of children's fitness. Significant but small effects were found for low maternal BMI, high psychosocial well-being and fruit \& vegetable intake as protective determinants. Sleep duration, breakfast intake, parental age and education and paternal BMI did not have a consistent significant effect on physical fitness. The role of determinants depended on children's sex and the specific PF component. Longitudinal analyses especially highlighted the importance of child's BMI as physical fitness determinant, independent of physical activity.

\section{Conclusion:}

BMI together with physical activity, diet and psychosocial factors are modifiable targets to enhance physical fitness. This calls for policy approaches that combine these factors in a systematic way. 


\section{Introduction}

Physical fitness (PF) is considered one of the most important health markers across the life course (Ortega et al. 2008) since it is a predictor of cardiovascular and all-cause mortality (Blair et al. 1989) but also of academic performance and psychosocial problems (Ortega et al. 2008). PF, physical exercise and physical activity (PA) are sometimes used as interchangeable concepts in the literature and must be distinguished from each other (Caspersen et al. 1985). PF is the capacity to perform PA, and makes reference to a full range of physiological and psychological qualities. PA is any body movement produced by muscle action that increases energy expenditure, whereas physical exercise refers to planned, structured, systematic and purposeful physical activity. In contrast with PA, which is related to the movements that people perform, PF is a set of attributes that people have or achieve (Caspersen et al. 1985) and consequently has a more direct link with overall health. Numerous studies have been conducted to identify the determinants of PA in children and adolescents, although with mixed findings (Sallis et al. 2000; Van Der Horst al. 2007; Craggs et al. 2011). Nevertheless, we are not aware of a study that explores the main determinants of PF components. Understanding PF determinants in children and their dependence on PA will lead to future opportunities for intervention and prevention programs targeting metabolic health in early life. Thus, the aim of this study is to explore several putative determinants of PF in European children aged 6-11 years, taking their PA levels into account. To assess PF, six fitness tests that cover the different domains of PF (cardio-respiratory fitness, muscular fitness and speed/agility) were administered. Sex differences were tested and some determinants were also examined from a longitudinal perspective. 


\section{Subjects and Methods}

\section{Study population}

The current study is based on data derived from the IDEFICS ("IDentification and prevention of dietary and lifestyle induced health EFfects In Children and infantS") study, which was conducted in 8 European countries (Belgium, Cyprus, Estonia, Germany, Hungary, Italy, Spain, Sweden) and aimed to determine the etiology of overweight, obesity and related disorders in children, and to evaluate a tailored primary prevention program (Ahrens et al. 2011). The cities recruited in the study were not always representative for the country. Data was collected from a baseline survey (T0; $\mathrm{N}=16228$; children aged 2-9 years) and 2-year follow-up survey (T1; $\mathrm{N}=13622$ ). From the follow-up sample (T1), 4903 (50.6\% girls) children had valid data for all tested determinants: body mass index (BMI), psychosocial well-being, dietary habits, parental age, parental BMI and educational attainment. Included versus excluded subjects did not differ significantly in age, sex, parental educational attainment and BMI. Since PF can only be measured accurately starting at the age of 6 (EUROFIT tests 1988), only children 6-11 years were included in this study and therefore the cross-sectional analysis was based on T1, while a longitudinal analysis was based on change between T0 and T1. The population flow chart is described in Figure 1. The study was approved by the Research Ethics Committees at each study center involved and was performed following the ethical guidelines of the Declaration of Helsinki 1961 (revision of Edinburgh 2000). Written informed consent was obtained from all parents or guardians. 


\section{Measurements protocol}

For quality management, all measurements followed detailed standard operating procedures that were pretested (Suling et al. 2011). Field personnel from each study center participated in the central trainings (Ahrens et al. 2011). The measurements were collected at participating schools and questionnaires were filled in by the parents at home.

\section{Physical fitness assessment}

PF components were assessed by the Eurofit test battery. Its validity and reliability in young people has been previously published (Ruiz et al. 2011).

\section{Cardio-respiratory fitness}

Cardio-respiratory fitness (CRF) was measured by the progressive 20mSRT shuttle run test (Leger et al. 1988). Participants were required to run between 2 lines $20 \mathrm{~m}$ apart while keeping pace with audio signals emitted from a prerecorded CD. The initial speed was $8.5 \mathrm{~km} / \mathrm{h}$ and was increased by $0.5 \mathrm{~km} / \mathrm{h}$ per minute (Leger et al. 1988). The test was finished when the participant stopped because of fatigue or failed to reach the end lines concurrent with the audio signals on 2 consecutive occasions. The test was performed once and the amount of shuttles was registered. Shuttles were converted to stages to calculate maximal oxygen consumption (VO2max) using Leger's equation (Leger et al. 1988). A greater number of shuttles and higher VO2max indicate better CRF. This test was not performed in Italian children (N=574). Muscular strength of lower- and upper-limb Upper-limb isometric strength was measured with the handgrip strength test using a hand dynamometer with adjustable grip (TKK 5101 Grip D; Takey). The child had to stay in a standard bipedal position with the arms in complete extension holding the dynamometer. The 
dynamometer was adjusted to sex and hand size for each child (Espana-Romero et al. 2008). The score was calculated as the average of right and left handgrip strength. Higher scores indicate better performance.

Lower-limb explosive strength was evaluated with the standing long jump test (Castro-Pinero et al. 2010). The child jumped as far as possible with feet together on a nonslip hard surface. The test was performed twice and the best score was recorded in centimeters. Higher scores indicate better performance.

Speed and agility

The $40 \mathrm{~m}$ sprint test measured the maximum running speed. Two attempts were allowed, the best score was retained. In this test, lower scores indicate better performance.

The flamingo balance test measured the ability to balance successfully on a single leg. The child has to bend his/her free leg backwards and grip the back foot with his/her hand on the same side. The child was given one try to become familiar with the test. The number of attempts needed to stand on one leg for 1 minute was counted for each leg. Children were excluded if they had put down the other foot 15 times or more within the first 30 s. The test score was calculated as the sum of attempts with both legs. Lower scores indicate better performance.

The back-saver sit-and-reach test measures the flexibility of the hamstring muscles (Meredith et al. 2007). The participant was required to sit with the untested leg bent at the knee; the tested leg was placed straight with the foot placed against the box. The participant slowly reached forward as far as possible. The score was recorded to the nearest centimeter, twice for each leg. The score was calculated as the average of both sides. Higher scores indicate better performance. 


\section{Anthropometric measurement}

International guidelines for anthropometry in children were used (Stomfai et al. 2011). Body weight $(\mathrm{kg})$ and height $(\mathrm{cm})$ were measured in barefoot children, clothed in underwear. An adapted version of the electronic TANITA scale (Tanita BC 420 SMA, Tanita Europe GmbH, Sindelfingen, Germany) was used to measure weight to the nearest $0.1 \mathrm{~kg}$ and a portable stadiometer (Seca 225, Birmingham, UK) to measure height at the nearest $0.1 \mathrm{~cm}$. BMI was calculated as body weight $(\mathrm{kg})$ divided by height $(\mathrm{m})$ squared. Age and sex adjusted BMI zscores were calculated following Cole's method and obesity/overweight classification was done using the extended IOTF cut-offs (Cole and Lobstein 2012).

\section{Physical activity}

Actigraph accelerometers (Actigraph MTI; FL, USA) were worn at the right hip to measure physical activity. Recordings were considered reliable if the device was worn for at least $6 \mathrm{~h} / \mathrm{day}$ during at least 3 days ( 2 weekdays and 1 day of the weekend or holiday) (Ojiambo et al. 2011). PA was categorized as sedentary, light, moderate or vigorous PA according to the Evenson cut off points (Evenson et al. 2008).

\section{Psychosocial well-being}

Questions were included from the proxy reported KINDL for parents of children aged 7-17 years, a validated questionnaire for measuring health-related quality of life in children (http://www.kindl.org). Answers were given according to a 4-point Likert scale (never, rarely, sometimes, often/all the time), that was adapted from the original 5-point Likert scale of the KINDL. Only psychosocial well-being was considered, including the score of subscales on emotional well-being, self-esteem, family and friends. Higher scores indicate better well-being. 


\section{Dietary habits}

Information on dietary habits was obtained from a validated standardized Food Frequency Questionnaire which was parental reported. Only frequency data was available, not the portion (Bel-serrat 2014). We considered the reported frequency of breakfast consumption (Papoutsou et al. 2014) as well as fruit and vegetables as a marker of healthy dietary intake (Ciliska et al 2000).

\section{Sleep duration}

Information on sleep duration was collected by questionnaire from parental reported bedtime and get-up time, separately for weekdays and weekend. Average sleep duration was calculated as follows: $1 / 7 *(2 *$ weekend $+5 *$ weekday $)$.

\section{Parental factors}

Parental BMI was calculated using self-reported height and weight of the mother and father. Self-reported parental age was included. Parental education as an indicator of socioeconomic status was categorized using the International Standard Classification of Education (ISCED) (http://www.uis.unesco.org/Education/Pages/international-standard-classification-of education.aspx). The ISCED level was derived for the highest qualification levels of both parents using a scale from 0 to 6 but a re-categorization was done as follows: low education attainment (ISCED level 0-3) and high educational attainment i.e. post-secondary education (ISCED level 4-6).

\section{Statistical analysis}

All statistical calculations were performed in SPSS software, version 22.0 (IBM, New York, NY, USA), with a significance set at $P<0.05$. Independent sample-T-test and Chi-square tests were used to give full description about predictor and outcome variables and sex differences herein. 
The cross-sectional associations between determinant factors and PF components based on data derived from follow-up study (T1) were analyzed by linear regression using two separate analyses. In the first analysis, all PF components were tested together as one outcome using multivariate regression analyses. The effect size (partial eta squared) was interpreted as follows: 0.14 low; 0.39 moderate; 0.59 large (Cohen et al. 2003). In the second analysis, linear mixed models were used to investigate the influence of predictors on each component outcome separately. This multilevel method enables a two level model to adjust for the clustered design (children within countries) by using country as a random factor and to test the longitudinal change (two measurements within the individual) by including predictor and outcome factors of the two time points. In addition, the mixed models were also performed separately by sex since (1) theoretically, different relations might exist e.g. maternal characteristics might be more important for girls' PF than for boys' PF and (2) empirically, significant sex interaction terms were noticed for some predictors (psychosocial well-being, fruit and vegetables, PA, parental age). Furthermore, these linear mixed models were used to test some predictors longitudinally which might be changed over two years (lifestyle and BMI change between the T0 and T1 measurement wave). To get more insight in the role of PA in these relations, PA was included in the models in a second step. For all mentioned analyses, all predictor variables were included at once in the model and adjustment was done for the control versus intervention region to adjust for the IDEFICS intervention. 


\section{Results}

Descriptive statistics for girls and boys including determinant and outcome variables are shown in Table I. Although boys performed better than girls in CRF, upper- and lower-limb strength and speed, girls were better in balance and flexibility.

Multivariate regression analysis for the determinants of PF (Table II) showed significant associations with children's age, sex, BMI, PA, psychosocial well-being and frequency of fruit and vegetables intake. The effect size (partial eta squared) was highest for age, moderate for sex, BMI, PA and low for the other determinants.

All PF components were significantly associated with children's BMI and age, except flexibility was not associated with the child's BMI (Table III). While CRF and flexibility decreased by increasing age, muscular strength, speed and balance increased. Higher child's BMI was associated with lower CRF, higher upper-limb strength, less lower-limb strength, less speed and less balance. CRF was better in those with higher parental educational attainment, higher psychosocial well-being and lower maternal BMI. The upper-limb strength was positively associated with child's age and BMI. Lower-limb strength was positively associated with age, psychosocial well-being and maternal age, while it was negatively associated with parental educational attainment, parental BMI and paternal age. While speed was higher in children with high psychosocial well-being and less maternal BMI, flexibility was better in children with only higher psychosocial well-being. Balance was significantly better in children with higher parental educational attainment and less maternal BMI.

Interestingly some non-linearity was found in the effect of BMI (Figure2): e.g. a U-shape form was seen for speed in which the normal weight group was the best and balance was only worse 
in the obese group. In contrast, a perfect linear amelioration was seen with increasing BMI for upper-limb strength and an almost linear deterioration was seen for CRF and lower-limb strength.

As presented in Table IV, the significance of PF determinants could be different between boys and girls. The detected directions were similar to those in table III. Maternal BMI had a significant association with CRF, lower-limb strength, speed and balance in boys but not in girls. In contrast, psychosocial well-being was associated with speed and flexibility in girls but not boys.

Next, the role of PA was examined. All outcome variables had significant association with PA $(p<0.001)$, except for balance $(P=0.863$ and $P=0.702$ in boys and girls, respectively). After adjusting for PA, data were available in 2557 children for the multivariate analyses, but higher sample sizes were available for the separate PF outcomes. The results of the multivariate model (Table II) remained the same except that psychosocial well-being was not a significant predictor any more. Changes were also noticed in the mixed model's results (see tables III-IV).

Finally, table $\mathrm{V}$ presents the results of 2-year longitudinal analyses for specific determinants which might be changed over time (BMI, psychosocial well-being, breakfast, frequency of fruit and vegetables intake and PA). It revealed that change in all PF components could be predicted by child's BMI. With increasing BMI, upper-limb strength and balance improved but all other PF components diminished. The effects were strongest for CRF and lower-limb strength. PA, psychosocial well-being and breakfast had a positive longitudinal effect on CRF. Speed deteriorated by increased breakfast frequency, while balance improved by increased frequency of fruit and vegetable intake. 


\section{Discussion}

PA and PF among children and adolescents have been an increasing public health concern during the last decades, with health effects already in early life (Sallis et al. 2000; Van Der Horst al. 2007; Craggs et al. 2011). Previously published studies on PF determinants resulted in mixed findings which could be related to the great diversity in research designs, measurement approaches, populations studied, tested variables, and PA outcomes. The specific/additional value of our study is the use of several objectively-measured PF components in a heterogeneous group and the longitudinal analyses for some determinants which could change over two years. Children's characteristics, their lifestyle and parental factors were considered in the present analyses.

\section{Children's characteristics}

Findings of the current study revealed significant differences in PF between boys and girls. Boys performed better than girls in CRF, upper- and lower-limb strength and speed, while girls were better in agility (balance and flexibility). Older children performed better than younger children in all tests, except for the CRF and flexibility. These findings were consistent with literature, which highlighted sex and age differences in children and adolescents in PF (Dumith et al. 2010; De Miguel et al 2014). The sex and age differences in PF performance in our study might hence be related to effects of genetics, anatomy, physiology, behavior and social and physical environments.

BMI z-score was the only determinant which had very strong and consistent significant associations with PF in both cross-sectional and longitudinal analyses. Strongest BMI effects were seen on CRF and lower-limb strength. These significances and the effect size (partial eta 
squared $=0.269$ ) show that BMI-reduction is a very important factor to prevent or improve low PF, except for upper-limb strength and balance. Our findings concur with cross-sectional studies which have found an inverse correlation between PF and BMI (Dumith et al 2010; Fogelholm et al 2008) but an advantageous effect on handgrip (Deforche et al. 2003). Our findings also show that PA is an important predictor of PF and that the association of PF and obesity remains after adjusting for PA. But what do these complex PA-PF-obesity relations now mean for public health? A recent review has detected a lot of uncertainty until now (Rauner et al. 2013). For improvement of PF in a preventive perspective, overweight related lifestyle should be targeted. For intervention, it has previously been recommended to encourage obese youth in PA to start with static strength exercise (Deforche et al. 2003). After all, overweight people cannot directly achieve better PF values because of their overweight status giving problems to perform well on PF tests and to practice high intensity cardio-respiratory activities.

\section{Children's lifestyle}

A daily breakfast might be considered as a healthy dietary habit. Indeed, daily reported breakfast consumption was associated with a healthier BMI, healthier lipid profiles and higher PA in European children (Papoutsou et al. 2014). However, skipping breakfast was not associated with lower PA, lower PF or higher sedentary time in European adolescents (CuencaGracia et al. 2013) and similar results were also published on British adolescents (Corder et al. 2011). Findings in the present study revealed no association between reported breakfast consumption and PF overall. Surprisingly, after adjustment for sex and PA, even an unfavorable effect of breakfast intake was found in boys. However, the longitudinal analyses detected a positive association of reported breakfast with CRF. This shows that the effect might differ 
depending on the type of PF. Insufficient data about the quality of reported breakfast consumption limits the discussion of these results.

Our findings showed that a higher reported intake of fruit and vegetables (as a marker for healthy dietary habits) was associated with better PF. This was the case for lower-limb strength and balance, mainly in girls. The longitudinal analyses revealed that fruit and vegetable intake was only important for a better balance. Since some significances remained after adjustment for PA, these relations are not solely explained by a healthier lifestyle but perhaps might be related to a better nutrient availability for muscle growth and related physiology (Lampe 1999). Sleep duration has been tested as determinant for PF since some studies have reported an association between short sleep duration and obesity in adults (Kohatsu et al. 2006). Moreover, longer sleep duration might give less possibilities for being active. The National Sleep Foundation in Washington-USA recommends children aged 5-12 to have 10-11 hours of sleep (http://www.sleepfoundation.org/article/sleep-topics/children-and-sleep). Our cohort had a mean sleep duration of 9.7 hours, showing that half of our population may have at least some lack of sleep. This suggests that lack of sleep is an important public health problem that might influence PF. Longer sleep duration was indeed associated with stronger lower-limbs in boys but also with worsened flexibility in girls. To the best of our knowledge, no previous study has investigated the influence of sleep duration on PF. Some authors have studied the effect of sleep duration on PA and have found that children who spent more time sleeping spent less time being physically active (Laurson et al. 2014); however, other authors did not find any association between PA and sleep duration (Ortega et al. 2011b). Consequently, more in-depth studies are necessary, also taking into account sleep quality. 
Psychosocial well-being was a last lifestyle-related determinant that was tested since low wellbeing might decrease the motivation to participate in activity. Indeed, cross-sectionally wellbeing was beneficial for fitness, especially for CRF, lower-limb strength, speed and flexibility. This association was observed in boys and girls, but more prominently in girls. After adjustment for PA, some of the associations disappeared, especially the relation with CRF and speed. Longitudinal analyses confirmed the important impact of psychosocial well-being on CRF.

\section{Parental factors}

Parents are important influencers of children's behavior. There is inconclusive information about whether associations exist between children's PF and parental age and BMI.

Results from the current study showed only few associations between parental age and children's PF. In addition, almost all significances disappeared after adjustment for PA. Parental age was also not significant in the multivariate analysis.

Maternal BMI had an important effect on PF in our sample. Lower maternal BMI resulted in higher CRF, higher speed and stronger upper-and lower-limbs in both sexes but more specific in boys. Most of these associations were independent of the child's PA. Paternal BMI did not show an effect on children's PF. These results highlighted a major maternal influence in determination of children's PF. Less maternal BMI might be due to their healthy diet and PA which affect their children.

Some uncertainties surround educational attainment differences in PF. Men and women from higher educational attainment are involved in more sport and recreational activity (Macintyre et al. 2004) and are probably more aware of the health effects. Indeed, a significant positive association between parental educational level and their child's PA level has previously been 
found (Kimm et al. 2002). In contrary, another study found that maternal education was not cross-sectionally nor longitudinally predictive of children's PA or sedentary behaviors (Ball et al. 2009). In the present study, the findings revealed better CRF, lower-limb strength and balance in both boys and girls with high parental educational attainment. Most of these significances can be explained by higher PA in high educational attainment since the significant association disappeared after adjustment for PA. In contrast, socioeconomic status influenced PF in European adolescents independently of PA (Jimenez Pavon et al. 2010).

\section{Strengths and limitations}

The main strengths of the current study are: (a) a large sample of European children; (b) the standardized use of different fitness components; (c) a well-balanced sex distribution which enables sex-specific data; (d) longitudinal analyses to explore some determinants which could change over two years; (e) an adjustment for PA to see the effects independent of PA; (f) the use of validated questionnaires (e.g. well-being, diet) and objective methods (e.g. physical activity, BMI). To our knowledge, no similar studies have been conducted yet.

The current study is subject to certain limitations. Many children did not have valid and complete data for all necessary variables. Thus, the number of included children dramatically decreased which lowered our power for the longitudinal analyses and PA adjustments. Concerning reported breakfast intake, information was not available on what children usually eat as breakfast, making it difficult to discuss our findings in the context of 'a healthy dietary routine'. Parental proxy reporting of child's diet and well-being are prone to error. Finally, parental PA was not tested due to insufficient data. 


\section{Conclusion}

This study identified some unmodifiable but more importantly also some modifiable predictors of $\mathrm{PF}$ to be included in prevention and intervention. Moreover, the determinants differ depending on the type of PF and the child's sex. Age, sex, children's BMI and PA were the strongest determinants of children's PF, independent from each other. Older children performed better than younger children, except for CRF and flexibility. Boys performed better than girls in CRF, upper- and lower-limb strength and speed while girls were better in balance and flexibility. Longitudinally, a high BMI was associated with a decline in CRF, speed, flexibility and lower-limb strength and with an increase in upper-limb strength and balance. PA was associated with higher PF components except for balance. Significant but small effects were found for low maternal BMI, high psychosocial well-being and high fruit and vegetable intake as protective determinants.

A new strong perspective of this study is that PF can be an important health factor separate from PA since many determinants (e.g. fruit/vegetables and BMI) still had an effect on PF independent of PA. Especially for BMI, there are complex implications for intervention since PF cannot be improved without increasing PA. Consequently, BMI and PA together should be taken into account when designing interventions to improve PF as a general health marker but also nutritional interventions might decrease BMI and consequently increase PF. 


\section{References}

Ahrens W, Bammann K, Siani A, et al (2001): The IDEFICS cohort: design, characteristics and participation in the baseline survey. Int J Obes 35:S3-S15. doi: 10.1038/ijo.2011.30.

Ball K, Cleland VJ, Timperio AF et al (2009). Socioeconomic position and children's physical activity and sedentary behaviors: longitudinal findings from the CLAN Study. J Phys Act Health $6(3): 289-298$.

Bel-Serrat S, Mouratidou T, Pala V et al (2014). Relative validity of the Children's Eating Habits Questionnaire-food frequency section among young European children: the IDEFICS Study. Public Health Nutr 17(2):266-76. doi: 10.1017/S1368980012005368.

Blair SN, Kohl HW, Paffenbarger RS JR et al (1989). Physical fitness and all-cause mortality. A prospective study of healthy men and women. JAMA 262: 2395-401.

Caspersen CJ, Powell KE, Christenson GM (1985). Physical activity, exercise, and physical fitness: definitions and distinctions for health-related research. Public Health Rep 100(2):126-31.

Castro-Pinero J, Ortega FB, Artero EG et al (2010). Assessing muscular strength in youth: usefulness of standing long jump as a general index of muscular fitness. J Strength Cond Res 24: 1810 -1817. doi: 10.1519/JSC.0b013e3181ddb03d.

Cohen J, Cohen P, West SG et al (2003). Applied multiple regression/correlation analysis for the behavioral sciences. Third Edition. New York: Routledge.

Cole TJ, Lobstein T (2012). Extended international (IOTF) body mass index cut-offs for thinness, overweight and obesity. PediatrObes 7(4):284-94. doi: 10.1111/j.2047-6310.2012.00064.x. Corder K, van Sluijs EM, Steele RM et al (2011). Breakfast consumption and physical activity in British adolescents. Br J Nutr 105(2):316-21. doi: 10.1017/S0007114510003272. 
Council of Europe Committee for the Development of Sport. Eurofit (1988): Handbook for the EUROFIT Tests of Physical Fitness. Rome, Italy: Edigrafeditorialegrafica.

Ciliska D , Miles E , O'Brien M et al (2000). Effectiveness of community-based interventions to increase fruit and vegetable consumption. J. NutrEduc 32:341-352.

Craggs C, Corder K, van Sluijs EMet al (2011). Determinants of change in physical activity in children and adolescents: a systematic review. Am J Prev Med 40(6):645-58.

doi: 10.1016/j.amepre.2011.02.025.

Cuenca-García M, Ruiz JR, Ortega FB, Labayen I et al (2013). Association of breakfast consumption with objectively measured and self-reported physical activity, sedentary time and physical fitness in European adolescents: the HELENA Study. Public Health Nutr 11:1-11. doi: $10.1017 /$ S1368980013002437.

Deforche B, Lefevre J, De Bourdeaudhuij I et al (2003). Physical fitness and physical activity in obese and non obese Flemish youth. Obes Res 11: 434-441.

De Miguel-Etayo P, Gracia-Marco L, Ortega FB et al (2014).Physical fitness reference standards in European children: the IDEFICS study. Int J Obes 38 Suppl 2:S57-66.

doi: 10.1038/ijo.2014.136.

Dumith SC, Ramires VV, Souza MA et al (2010). Overweight/obesity and physical fitness among children and adolescents. Journal of Physical Activity \& Health, 7(5):641-648.

España-Romero V, Artero EG, Santaliestra-Pasias AM et al (2008). Hand span influences optimal grip span in boys and girls aged 6 to 12 years. J Hand Surg Am33(3):378-84.

doi: 10.1016/j.jhsa.2007.11.013. 
Evenson KR, Catellier DJ, Gill K et al (2008). Calibration of two objective measures of physical activity for children. J Sports Sci 26:1557 - 1565. doi: 10.1080/02640410802334196.

Fogelholm M, Stigman S, Huisman Tet al (2008). Physical fitness in adolescents with normal weight and overweight. Scand J Med Sci Sports 18(2):162-70.

Jiménez Pavón D, Ortega FP, Ruiz JR et al (2010). Socioeconomic status influences physical fitness in European adolescents independently of body fat and physical activity: the HELENA study. NutrHosp 25(2):311-6.

Kimm SY, Glynn NW, Kriska AM et al (2002). Decline in physical activity in black girls and white girls during adolescence. N Engl J Med 347(10):709 -15.

Kohatsu ND, Tsai R, Young $T$ et al 2006. Sleep duration and body mass index in a rural population. Arch Intern Med 18;166(16):1701-5 .

Lampe JW (1999). Health effects of vegetables and fruit: assessing mechanisms of action in human experimental studies. Am J ClinNutr 70(3 Suppl):475S-490S.

Laurson KR, Lee JA, Gentile DA et al (2014). Concurrent Associations between Physical Activity, Screen Time, and Sleep Duration with Childhood Obesity. Obes 9;2014:204540. doi: $10.1155 / 2014 / 204540$.

Leger LA, Mercier D, Gadoury C et al (1988). The multistage 20 meter shuttle run test for aerobic fitness. J Sports Sci 6:93-101.

Macintyre S, Mutrie N (2004). Socio-economic differences in cardiovascular disease and physical activity: stereotypes and reality. J R Soc Health 124(2):66-69.

Meredith, M., Welk, G (2007). Fitness gram-Activity gram Test Administration Manual. Human Kinetics : Champaign, IL, USA. 
National Sleep Foundation. Children and sleep-information on sleep health and safety.2011, http://www.sleepfoundation.org/article/sleep-topics/children-and-sleep.

Ojiambo R, Cuthill R, Budd H et al (2011). Impact of methodological decisions on accelerometer outcome variables in young children. Int J Obes 35:S98-S103. doi: 10.1038/ijo.2011.40.

Ortega FB, Ruiz JR, Castillo MJet al (2008a). Physical fitness in childhood and adolescence: a powerful marker of health. Int J Obes32:1-11. doi:10.1038/sj.ijo.0803774.

Ortega FB, Ruiz JR, Labayen I et al (2011b). Sleep duration and activity levels in Estonian and Swedish children and adolescents. European Journal of Applied Physiology 111(10):2615-2623. doi: 10.1007/s00421-011-1883-6.

Papoutsou S, Briassoulis G, Wolters M et al (2014). No breakfast at home: association with cardiovascular disease risk factors in childhood. Eur J ClinNutr 68(7):829-34.

doi: 10.1038/ejcn.2014.88.

Rauner A, Mess F, Woll A (2000). The relationship between physical activity, physical fitness and overweight in adolescents: a systematic review of studies published in or after 2000 . BMC Pediatr 1;13:19. doi: 10.1186/1471-2431-13-19.

Ruiz JR, Castro-Pinero J, Espana-Rom ero V et al (2011). Field-based fitness assessment in young people: the A LPHA health-related fitness test battery for children and adolescents. Br J Sports Med 45:518- 524. doi: 10.1136/bjsm.2010.075341.

Sallis JF, Prochaska JJ, Taylor WC (2000). A review of correlates of physical activity of children and adolescents. Med Sci Sports Exerc 32:963-975.

Stomfai S, Ahrens W, Bammann K et al (2011). Intra and inter observer reliability in anthropometric measurements in children. Int J Obes 35:S45-S51. doi: 10.1038/ijo.2011.34. 
Suling M, Hebestreit A, Peplies J et al (2011). Design and results of the pretest of the IDEFICS study. Int J Obes 35:S30-S44. doi: 10.1038/ijo.2011.33.

United Nations Educational Scientific and Cultural Organization International Standard Classification of Education (ISCED). 2006. http://www .uis.unesco.org/Education/Pages/ international-standard -classification-of-education.aspx (accessed 2 February 2012).

Van Der Horst K, Paw MJ, Twisk JW et al (2007). A brief review on correlates of physical activity and sedentariness in youth. MedSci Sports Exerc 39(8):1241-1250.

doi: 10.1249/mss.0b013e318059bf35 


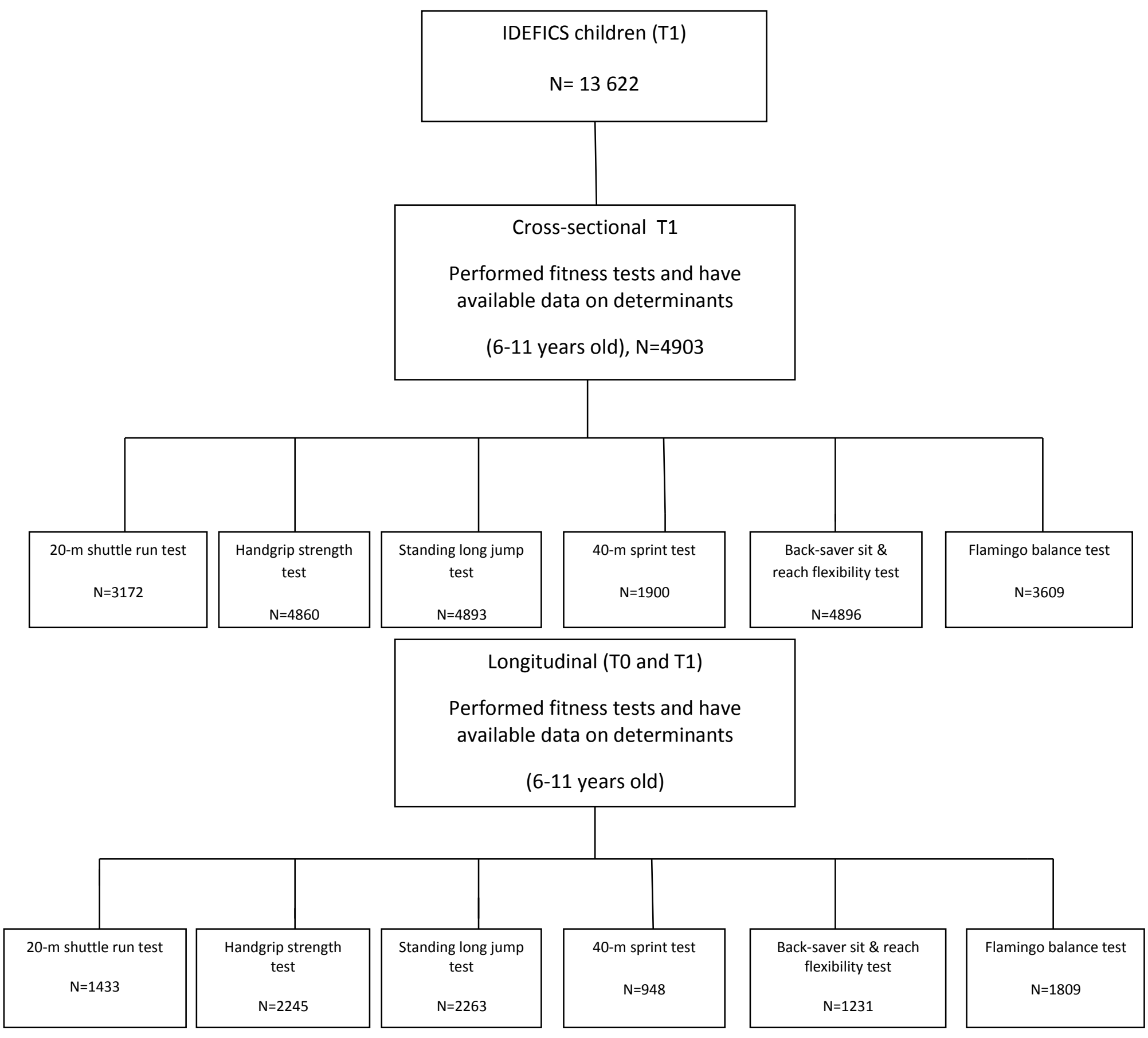

Figure 1. Flow chart of the population selected for this article. IDEFICS ("IDentification and prevention of dietary and lifestyle induced health EFfects In Children and infantS") 


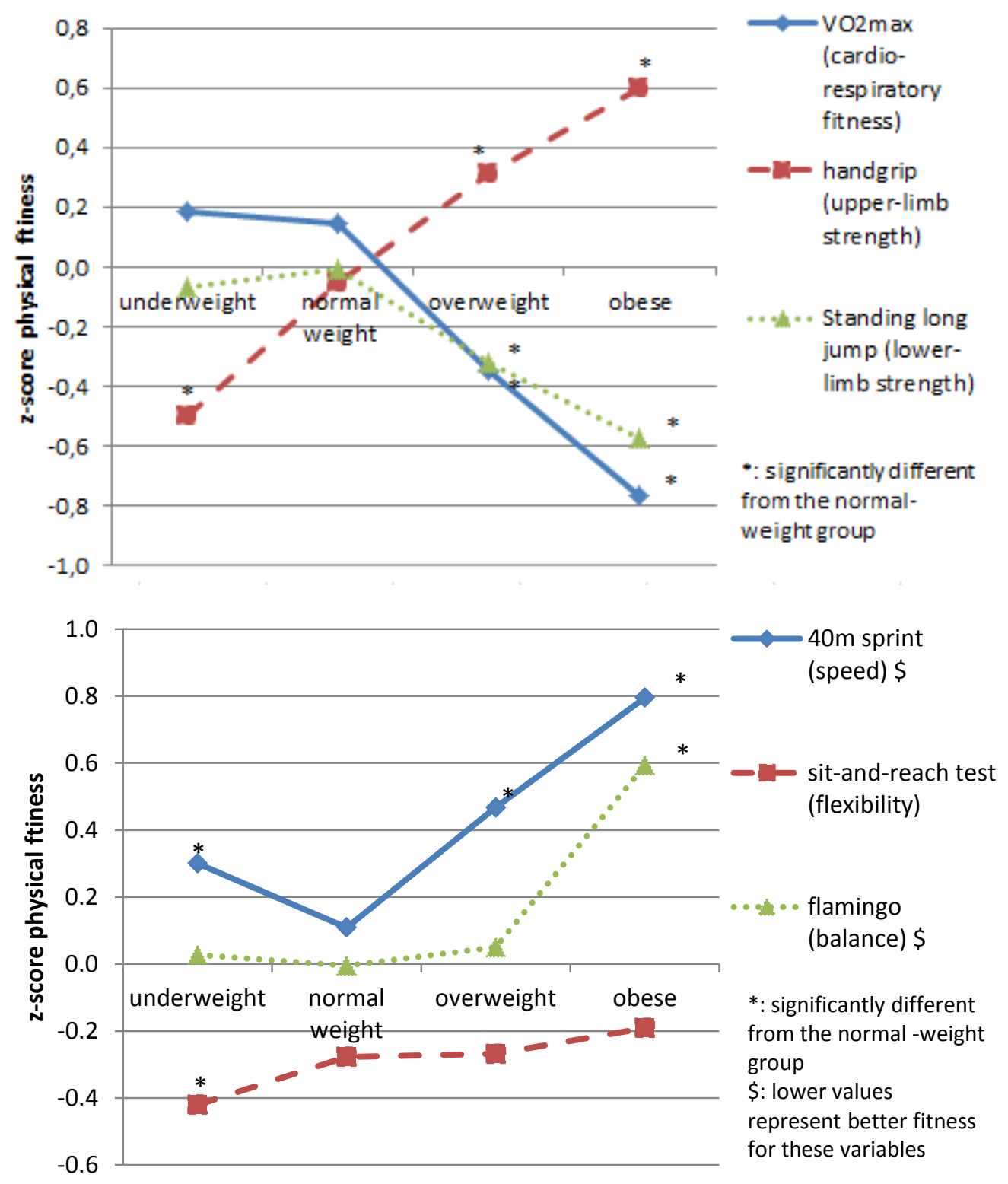

Figure2: Patterns of physical fitness over the different body mass index categories using cross-sectional mixed model regression. 
Table I: Descriptive table including determinant and outcome variables in T1.

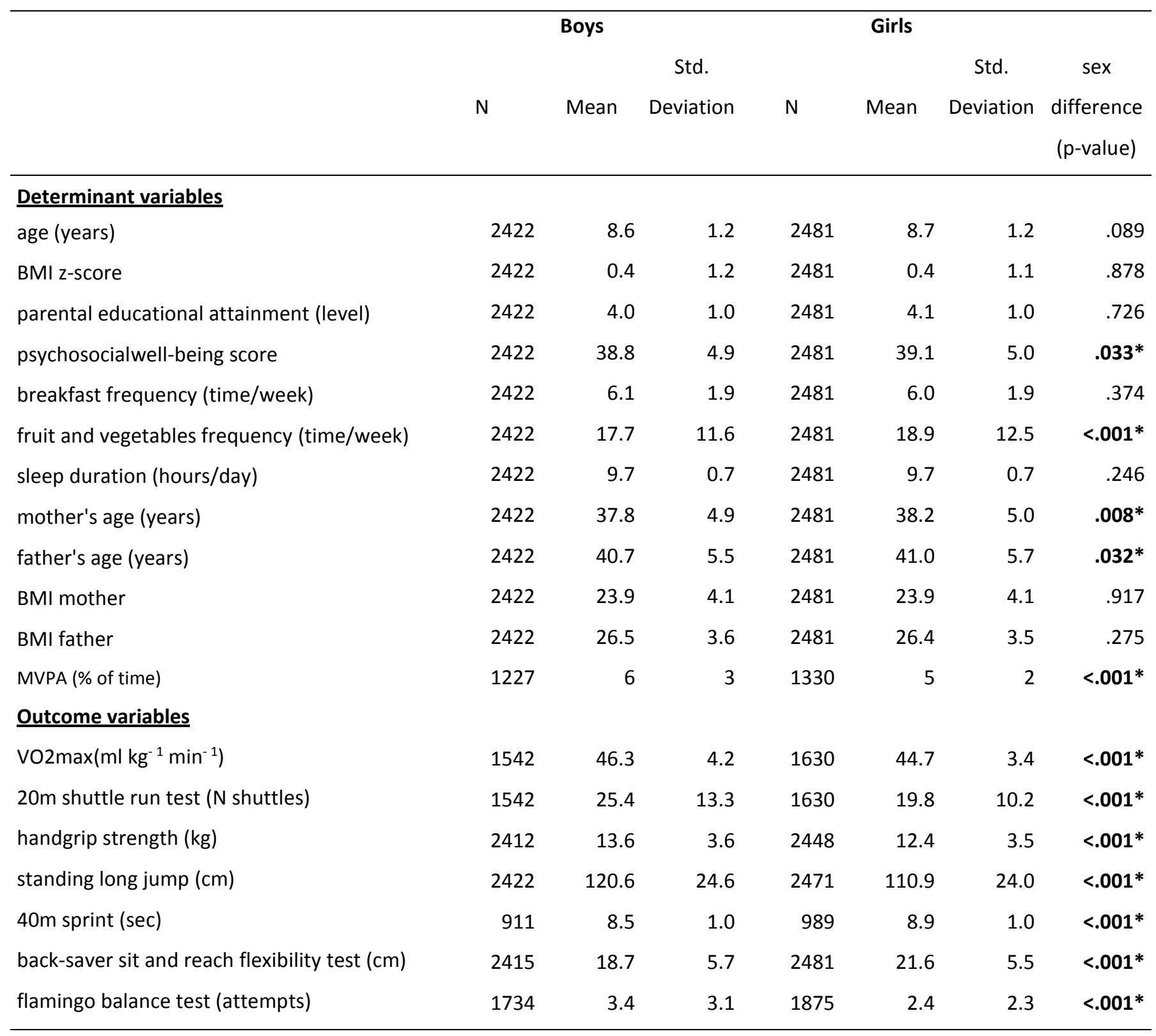

$\mathrm{BMI}=$ body mass index, $\mathrm{VO} 2 \mathrm{max}=$ maximal oxygen consumption, MVPA=moderate-to-vigorous physical activity.

$* P<0.05$, statistically significant association. 
Table II: Multivariate regression: The association between overall physical fitness (outcome) and determinant factors

\begin{tabular}{lcc}
\hline Determinants & $\begin{array}{c}\text { Partial Eta Squared } \\
\text { (=effect size) }\end{array}$ & p-value \\
\hline country & .116 & $<.00 \mathbf{1}^{*}$ \\
sex & .316 & $<.00 \mathbf{1}^{*}$ \\
age (years) & .649 & $<.00 \mathbf{1}^{*}$ \\
BMIz-score & .269 & $<.00 \mathbf{1}^{*}$ \\
parental educational attainment (low-high) & .008 & .271 \\
psychosocial well-being score & .016 &. $\mathbf{0 1 2}$ \\
Breakfastbreakfast (time/week) & .005 & .727 \\
fruit and vegetables (time/week) & .014 & $.037^{*}$ \\
sleep duration (hours/day) & .010 & .164 \\
age mother (years) & .006 & .511 \\
age father (years) & .004 & .715 \\
BMI mother & .009 & .198 \\
BMI father & .006 & .492 \\
MVPA (\% of time) & .144 & $<.001 *$ \\
\hline
\end{tabular}

$\mathrm{BMI}=$ body mass index.MVPA=moderate-to-vigorous physical activity. ${ }^{*} \mathrm{P}<0.05$, statistically significant association.\# Disappearance of the significance after adjustment for moderate-to-vigorous physical activity. Multivariate regression is a regression that automatically combines several outcomes (we selected the six fitness components) to one outcome and models the predictive value of a set of determinants on this outcome. 


\section{Table III: Multiple linear mixed model: The association between separate physical fitness components (outcome) and determinant factors.}

\begin{tabular}{|c|c|c|c|c|c|c|c|c|c|c|c|c|c|c|c|c|c|c|c|c|c|}
\hline & \multicolumn{6}{|c|}{ Cardio-respiratory fitness } & \multicolumn{6}{|c|}{ Muscular strength } & \multicolumn{9}{|c|}{ Speed and agility } \\
\hline & \multicolumn{3}{|c|}{$\begin{array}{c}\mathrm{Vo}_{2} \max \left(\mathrm{ml} \mathrm{kg}^{-1} \mathrm{~min}^{-1}\right) \\
\mathrm{N}=3172\end{array}$} & \multicolumn{3}{|c|}{$\begin{array}{l}\text { 20m shuttle run } \\
\qquad \begin{array}{c}\text { (shuttles) } \\
\mathrm{N}=3172\end{array}\end{array}$} & \multicolumn{3}{|c|}{$\begin{array}{l}\text { Handgrip } \\
\text { strength }(\mathrm{kg}) \\
\mathrm{N}=4860\end{array}$} & \multicolumn{3}{|c|}{$\begin{array}{l}\text { Standing long } \\
\text { jump (cm) } \\
\mathrm{N}=4893\end{array}$} & \multicolumn{3}{|c|}{$\begin{array}{c}\text { 40m sprint } \\
\qquad \begin{array}{c}\text { (sec) } \\
\mathrm{N}=1900\end{array}\end{array}$} & \multicolumn{3}{|c|}{$\begin{array}{l}\text { Sit-and-reach flexibility test } \\
\qquad \begin{array}{l}(\mathrm{cm}) \\
\mathrm{N}=4896\end{array}\end{array}$} & \multicolumn{3}{|c|}{$\begin{array}{l}\text { Flamingo } \\
\text { balance } \\
\text { (attempts) } \\
\mathrm{N}=3609\end{array}$} \\
\hline & $\beta$ & B & $P$ & $\beta$ & B & $P$ & $\beta$ & B & $P$ & $\beta$ & B & $P$ & $\beta$ & B & $P$ & $\beta$ & B & $P$ & $\beta$ & B & $P$ \\
\hline age & -.273 & -.839 & $<.001^{*}$ & .354 & 3.375 & $<.001 *$ & .620 & 1.792 & $<.001^{*}$ & .349 & 6.833 & $<.001^{*}$ & -.503 & -.427 & $<.001^{*}$ & -.116 & -.536 & $<.001^{*}$ & -.352 & -.796 & $<.001 *$ \\
\hline $\begin{array}{l}\text { sex of the child } \\
\text { (girls as reference) }\end{array}$ & .391 & 1.522 & $<.001^{*}$ & .472 & 5.669 & $<.001^{*}$ & .369 & 1.343 & $<.001^{*}$ & .434 & 10.743 & $<.001^{*}$ & -.398 & -.355 & $<.001^{*}$ & -.493 & -2.885 & $<.001^{*}$ & 339 & .888 & $<.001^{*}$ \\
\hline BMI z-score & -.219 & -.733 & $<.001 *$ & -.245 & -2.527 & $<.001 *$ & .240 & .889 & $<.001 *$ & -.166 & -3.542 & $<.001^{*}$ & .139 & .128 & $<.001^{*}$ & .030 & .153 & .065 & .099 & 244 & $<.001 *$ \\
\hline $\begin{array}{c}\text { parental educational attainment } \\
\text { (high as reference) }\end{array}$ & -.142 & -.552 & $.001^{*}$ & -.095 & -1.140 & $.019 \#$ & -.011 & -.160 & .072 & -.074 & -1.846 & $.007^{*}$ & .061 & .066 & 170 & .006 & .037 & .856 & -.122 & -.136 & $.001^{*}$ \\
\hline psychosocial well-being & .051 & .040 & $.009 \#$ & .040 & .069 & $.029 \#$ & .016 & .009 & .247 & .042 & .211 & $.001 *$ & -.061 & -.013 & $.005 \#$ & .036 & .043 & $.020^{*}$ & -.025 & -.010 & .229 \\
\hline breakfast (t/week) & -.003 & -.003 & .932 & -.011 & -.071 & .532 & .001 & -.004 & .818 & -.002 & -.036 & $.822 \bullet$ & .028 & .015 & .225 & -.010 & -.031 & .514 & .-.010 & .015 & .541 \\
\hline fruit and vegetables (t/week) & .020 & .002 & .741 & .021 & .020 & .257 & .012 & .004 & 155 & .019 & .038 & .111• & -.036 & -.003 & .092 & -.010 & .004 & .501 & -.023 & -.003 & . 377 \\
\hline $\begin{array}{l}\text { sleep duration } \\
\text { (hours/day) }\end{array}$ & -.017 & -.093 & .436 & -.011 & -.248 & .605 & .017 & .085 & .167 & -.017 & -.585 & .214 & .003 & .021 & .906 & -.032 & -.252 & $.074 \bullet$ & -.009 & -.037 & .602 \\
\hline age mother & .022 & .016 & .449 & .022 & .051 & .813 & .008 & .000 & .979 & .053 & .253 & $.004^{*}$ & -.000 & -.000 & .979 & .007 & .008 & .741 & -.037 & -.020 & . 106 \\
\hline age father & .036 & .024 & 169 & .038 & .029 & $.127 \bullet$ & -.002 & -.006 & .531 & -.035 & -.153 & $.042 \#$ & -.016 & -.003 & .583 & -.040 & -.041 & .066 & -.003 & -.001 & .884 \\
\hline BMI mother & -.041 & -.038 & $.049^{*}$ & -.046 & -.131 & .013 & -.019 & -.010 & .261 & -.037 & -.216 & $.004^{*}$ & .072 & .018 & $.002^{*}$ & .010 & .014 & .506 & .040 & .026 & $.014 \#$ \\
\hline BMI father & -.027 & -.029 & .163 & -.027 & -.091 & .139 & -.012 & -.008 & .430 & -.025 & -.172 & $.043^{*}$ & .026 & .008 & $.224 \bullet$ & .006 & .010 & .687 & .002 & .001 & .847 \\
\hline
\end{tabular}

All determinants were added to the model at once. $\mathrm{VO}_{2} \mathrm{max}=$ maximal oxygen consumption. $* \mathrm{P}<0.05$, statistically significant association.\# Disappearance of the significance after adjustment for moderate-to-vigorous physical activity. •Significant after adjustment for moderate-to-vigorous physical activity.

$\beta=$ standardized regression coefficient, $B=$ unstandardized coefficient. 
Table IV: Multiple linear mixed model: The association between separate physical fitness components (outcome) and determinant factors stratified by boys and girls.

\begin{tabular}{|c|c|c|c|c|c|c|c|c|c|c|c|c|c|c|c|c|c|c|c|c|c|c|}
\hline & \multicolumn{7}{|c|}{ Cardio-respiratory fitness } & \multicolumn{6}{|c|}{ Muscular strength } & \multicolumn{9}{|c|}{ Speed and agility } \\
\hline & \multicolumn{4}{|c|}{$\mathrm{Vo}_{2} \max \left(\mathrm{ml} \mathrm{kg}^{-1} \mathrm{~min}^{-1}\right)$} & \multicolumn{3}{|c|}{$\begin{array}{l}\text { 20m shuttle run } \\
\text { (shuttles) }\end{array}$} & \multicolumn{3}{|c|}{$\begin{array}{l}\text { Handgrip } \\
\text { strength (kg) }\end{array}$} & \multicolumn{3}{|c|}{$\begin{array}{l}\text { Standing long } \\
\text { jump (cm) }\end{array}$} & \multicolumn{3}{|c|}{$\begin{array}{l}40 \mathrm{~m} \text { sprint } \\
\text { (sec) }\end{array}$} & \multicolumn{3}{|c|}{$\begin{array}{l}\text { Sit-and-reach flexibility test } \\
\qquad(\mathrm{cm})\end{array}$} & \multicolumn{3}{|c|}{$\begin{array}{c}\text { Flamingo } \\
\text { balance (attempts) }\end{array}$} \\
\hline & & $\beta$ & B & $P$ & $\beta$ & B & $P$ & $\beta$ & B & $P$ & $\beta$ & B & $P$ & $\beta$ & B & $P$ & $\beta$ & B & $P$ & $\beta$ & B & $P$ \\
\hline \multirow{2}{*}{ age } & boys & -.896 & -.707 & $<.001^{*}$ & .405 & 3.842 & $<.001^{*}$ & .616 & 1.763 & $<.001^{*}$ & .351 & 6.887 & $<.001^{*}$ & -.453 & -.385 & $<.001^{*}$ & -.164 & -.761 & $<.001^{*}$ & -.396 & -.894 & $<.001^{*}$ \\
\hline & girls & -1.26 & -.952 & $<.001^{*}$ & .309 & 2.993 & $<.001 *$ & .637 & 1.821 & $<.001^{*}$ & .354 & 6.915 & $<.001^{*}$ & -.534 & -.462 & $<.001^{*}$ & -.068 & -.315 & $.003^{*}$ & -.309 & -.704 & $<.001^{*}$ \\
\hline \multirow{2}{*}{ BMI z-score } & boys & -.901 & -.819 & $<.001^{*}$ & -.249 & -2.568 & $<.001^{*}$ & .285 & .887 & $<.001^{*}$ & -.190 & -4.019 & $<.001^{*}$ & .154 & .143 & $<.001^{*}$ & .040 & .203 & .079 & .122 & .305 & $<.001^{*}$ \\
\hline & girls & -.756 & -.648 & $<.001^{*}$ & -.241 & -2.491 & $<.001^{*}$ & .287 & .893 & $<.001^{*}$ & -.147 & -3.135 & $<.001^{*}$ & .124 & 115 & $<.001^{*}$ & .020 & .103 & .383 & . 079 & .194 & $<.001^{*}$ \\
\hline $\begin{array}{l}\text { parental } \\
\text { educational }\end{array}$ & boys & -.664 & -.707 & .009\# & -.117 & -1.410 & .073 & -.012 & -.044 & .734 & -.071 & -1.756 & .077 & .025 & .027 & .698 & -.068 & -.401 & .172 & 159 & .456 & $.004^{*}$ \\
\hline (high as reference) & girls & -.487 & -.458 & $.027 \#$ & -.092 & -1.010 & .058 & -.047 & -.268 & $.028 \#$ & 048 & -2.100 & $.026 *$ & -.089 & .096 & .140 & -.067 & -.278 & .316 & .091 & .262 & $.015 \#$ \\
\hline \multirow{2}{*}{$\begin{array}{l}\text { psychosocial well- } \\
\text { being }\end{array}$} & boys & .240 & .048 & .048\# & .054 & .054 & .068 & .013 & .008 & .472 & .045 & .225 & $.011 \#$ & -.042 & -.009 & .206 & .024 & .029 & .297 & -.014 & -.008 & .562 \\
\hline & girls & .157 & .031 & .099 & .022 & .130 & .315 & .011 & .009 & .407 & .042 & .211 & $.016^{*}$ & -.047 & -.015 & $.011 \#$ & .043 & .051 & $.048^{*}$ & -.027 & -.016 & .130 \\
\hline \multirow{2}{*}{ breakfast (/week) } & boys & -.006 & -.003 & .954 & .020 & -.128 & .474 & .007 & .014 & .637 & .013 & .006 & .976 & .049 & .027 & $.140 \bullet$ & .024 & -.073 & $.294 \bullet$ & .055 & .081 & $.049^{*}$ \\
\hline & girls & .000 & .000 & .966 & -.000 & -.000 & .996 & -.013 & -.025 & .384 & -.025 & -.064 & .774 & .019 & .007 & .684 & .003 & .011 & .863 & -.025 & -.037 & $.192 \bullet$ \\
\hline \multirow{2}{*}{$\begin{array}{c}\text { fruit and } \\
\text { vegetables (/week) }\end{array}$} & boys & -.063 & -.005 & .614 & .006 & .006 & .823 & .109 & .008 & .066 & .043 & .003 & .923 & -.033 & .007 & .682 & -.021 & -.010 & .351 & .005 & -.001 & .856 \\
\hline & girls & .085 & .007 & .356 & .025 & .024 & .251 & .014 & .001 & .778 & .737 & .063 & .054 & -.032 & -.002 & .263 & .036 & .072 & $.073^{*}$ & -.025 & -.005 & .156 \\
\hline \multirow{2}{*}{$\begin{array}{l}\text { sleep duration } \\
\text { (hours) }\end{array}$} & boys & -.214 & -.287 & .132 & -.037 & -.596 & .286 & .167 & .224 & $.013^{*}$ & -.723 & -.969 & .155 & .045 & .065 & .284 & -.021 & -.166 & .412 & .004 & .015 & .895 \\
\hline & girls & .046 & .061 & .670 & .010 & .164 & .693 & -.022 & -.030 & .723 & -.169 & -.263 & .686 & -.031 & -.045 & .401 & -.032 & -.252 & .187• & -.013 & -.015 & .835 \\
\hline \multirow{2}{*}{ age mother } & boys & .133 & .011 & .749 & .019 & .036 & .665 & .041 & -.019 & .203 & .075 & .365 & $.007^{*}$ & -.021 & -.004 & .659 & .016 & .018 & .629 & -.036 & -.019 & .354 \\
\hline & girls & .051 & .025 & .326 & .025 & .065 & .425 & -.021 & .024 & .329 & .034 & .164 & .168 & -.000 & -.000 & .990 & -.024 & -.027 & .445 & -.037 & -.020 & .154 \\
\hline \multirow{2}{*}{ age father } & boys & .246 & .043 & .154 & .061 & .129 & .141 & -.007 & -.005 & .676 & -.052 & -.226 & $.046 \#$ & -.039 & -.007 & .379 & -.086 & -.088 & .009\# & -.020 & -.010 & .579 \\
\hline & girls & .051 & .008 & .680 & .019 & -.040 & .506 & -.001 & -.005 & .794 & -.023 & .102 & .310 & -.000 & .001 & .797 & -.005 & -.005 & .850 & -.009 & -.004 & .705 \\
\hline \multirow{2}{*}{ BMI mother } & boys & -.244 & -.057 & .054 & -.082 & -.230 & $.008^{*}$ & -.008 & -.012 & .354 & -.039 & -.231 & $.028^{*}$ & .083 & .021 & $.014 \#$ & .017 & .023 & .457 & .051 & .034 & $.049 \#$ \\
\hline & girls & -.088 & -.020 & .410 & -.009 & -.025 & .695 & -.014 & -.028 & .156 & -.034 & -.199 & .060 & .068 & .017 & $.034^{*}$ & .009 & .013 & .674 & .032 & .021 & .099 \\
\hline \multirow{2}{*}{ BMI father } & boys & -.039 & -.011 & .745 & -.022 & -.075 & .445 & -.093 & -.025 & .111 & -.018 & -.126 & .303 & .012 & .003 & .710 & .016 & .027 & .460 & -.000 & 0.000 & .976 \\
\hline & girls & -.132 & -.063 & .163 & -.021 & -.072 & .336 & .020 & .005 & .719 & -.028 & -.263 & .686 & .036 & .010 & .225 & -.014 & -.023 & .512 & -.001 & -.001 & .913 \\
\hline
\end{tabular}


All determinants were added to the model at once. ${ }^{*} \mathrm{P}<0.05$, statistically significant association.\# Disappearance of the significance after adjustment for moderate-to-vigorous physical activity. $\bullet$ Significant after adjustment for moderate-to-vigorous physical activity. VO2max= maximal oxygen consumption; $\beta=$ standardized regression coefficient; $B=$ unstandardized coefficient. 
Table V: Two-year longitudinal effect of five determinants on change in physical fitness.

\begin{tabular}{|c|c|c|c|c|c|c|c|c|c|c|c|c|c|c|}
\hline & \multicolumn{4}{|c|}{ Cardiorespiratory fitness } & \multicolumn{4}{|c|}{ Muscular strength } & \multicolumn{6}{|c|}{ Speed and agility } \\
\hline & \multicolumn{2}{|c|}{$\begin{array}{c}\mathrm{VO}_{2} \max \left(\mathrm{ml} \mathrm{kg}^{-}\right. \\
\left.{ }^{1} \mathrm{~min}^{-1}\right) \\
\mathrm{N}=1433\end{array}$} & \multicolumn{2}{|c|}{$\begin{array}{c}\text { 20m shuttle run } \\
\text { (shuttles) } \\
\mathrm{N}=1433\end{array}$} & \multicolumn{2}{|c|}{$\begin{array}{c}\text { Handgrip } \\
\text { strength (kg) } \\
\quad \mathrm{N}=2245\end{array}$} & \multicolumn{2}{|c|}{$\begin{array}{l}\text { Standing long } \\
\text { jump }(\mathrm{cm}) \\
\mathrm{N}=2263\end{array}$} & \multicolumn{2}{|c|}{$\begin{array}{c}\text { 40m sprint } \\
\begin{array}{c}\text { (sec) } \\
N=948\end{array}\end{array}$} & \multicolumn{2}{|c|}{$\begin{array}{l}\text { Sit-and-reach } \\
\text { flexibility test } \\
(\mathrm{cm}) \mathrm{N}=1231\end{array}$} & \multicolumn{2}{|c|}{$\begin{array}{l}\text { Flamingo } \\
\text { Balance test } \\
\text { (attempts) } \\
\mathrm{N}=1809\end{array}$} \\
\hline & $\beta$ & Sig. & $\beta$ & Sig. & $\beta$ & Sig. & $\beta$ & Sig. & $\beta$ & Sig. & $\beta$ & Sig. & $\beta$ & Sig. \\
\hline BMI z-score & -.091 & $.003^{*}$ & -.178 & $<.001 *$ & .070 & $<.001 *$ & -.127 & $<.001^{*}$ & .060 & $.036 *$ & -.066 & $.003 *$ & -.068 & $.004^{*}$ \\
\hline $\begin{array}{l}\text { psychosocial well- } \\
\text { being }\end{array}$ & .080 & $.008^{*}$ & -.110 & .002 & .024 & .136 & .025 & .174 & .001 & .953 & .034 & .132 & .000 & .974 \\
\hline $\begin{array}{c}\text { breakfast } \\
\text { (time/week) }\end{array}$ & .063 & .031 & -.047 & .203 & -.002 & .875 & -.019 & .309 & .076 & $.008^{*}$ & -.021 & .364 & -.001 & .944 \\
\hline $\begin{array}{l}\text { fruit and vegetables } \\
\qquad \text { (time/week) }\end{array}$ & .062 & .106 & .007 & .841 & -.012 & .449 & .022 & .206 & -.044 & .114 & -.022 & .307 & -.079 & $.002 *$ \\
\hline MVPA (\%) & .161 & $<.001^{*}$ & .120 & $<.001 *$ & .040 & .078 & .011 & .664 & .021 & .555 & .016 & .588 & .023 & .473 \\
\hline
\end{tabular}

Results are based on mixed model analyses using T0 and T1 data for determinants and outcome. ${ }^{*} \mathrm{P}<0.05$, statistically significant association. $\mathrm{BMI}=$ body mass index, $\mathrm{VO} 2 \mathrm{max}=$ maximal oxygen consumption, $\beta=$ standardized regression coefficients, MVPA= moderate-to-vigorous physical activity. 


\section{ACKNOWLEDGEMENTS}

This work was done as part of the IDEFICS Study (www.idefics.eu). We gratefully acknowledge the financial support of the European Community within the Sixth RTD Framework Programme Contract No. 016181 (FOOD). Mahmoud Zaqout was financially supported by Flemish University Council -University Development Cooperation (VLIR-UOS). The information in this document reflects the author's view and is provided as is. The authors want to thank the participating children and their parents for their voluntary participation. 